\title{
Pulmonary Alveolitis
}

National Cancer Institute

\section{Source}

National Cancer Institute. Pulmonary Alveolitis. NCI Thesaurus. Code C35482.

Inflammation of the alveoli of the lung. 